\title{
Pausing at the Brink of Interdisciplinarity: Power and Knowledge at the Meeting of Social and Biophysical Science
}

\author{
Dena P. MacMynowski ${ }^{1}$
}

\begin{abstract}
Interdisciplinary environmental research has been deemed essential to addressing the dynamics of coupled social-biophysical systems. Although decades of scholarship in science and technology studies (STS) take the analysis of interdisciplinarity out of the realm of anecdote, there is almost no overlap between this literature and discussions of interdisciplinarity in ecology-oriented journals. The goals of researchers in these areas are quite different, and thus far, their analyses of interdisciplinarity have been incommensurate with each other's purposes. To introduce an STS perspective into how environmental scientists think about interdisciplinarity, I argue that biophysical and social scientists are not just bringing information and different understandings of biophysical and social systems to the intellectual table. Those knowledge claims have differential power associated with them: within the sciences, between social and biophysical science, and between science and society. Power can manifest in many ways, e.g., individual scientific status, the most accepted account of an environmental problem, inclusion or exclusion of researchers, or perceived relevance of research to policy decisions. I propose four possible scenarios: conflict, tolerant ambivalence, mutual identification, cooperation, and fundamental transformation for how an interdisciplinary undertaking might unfold. Then, to constructively confront the relationship between power and knowledge, I outline a three stage process to enhance the transparent development of interdisciplinary research. First, there is differentiation of the analytical elements of the research, then clarification of purposes, and finally, the steps toward intellectual synthesis. As core differences are encountered, e.g., "subjectivity" vs. "objectivity," active engagement with these issues will be essential to successful communication, collaboration, and innovation.
\end{abstract}

Key Words: interdisciplinarity; philosophy of science; power; power/knowledge; social-biophysical systems; research methods; transdisciplinarity.

\section{INTRODUCTION}

Interdisciplinary environmental research has been the subject of much discussion and debate over the last decade or so. How do current institutional structures create obstacles to increasing interdisciplinary research (Naiman 1999)? What are possible integrative frameworks for social and ecological knowledge (Pickett et al. 1999)? How do scientists connect interdisciplinary research with societal needs (Bradshaw and Bekoff 2001)? What is the relationship of the discipline to interdisciplinarity undertakings (Daily and Ehrlich 1999)? Can existing academic structures support interdisciplinary education (Golde and Gallagher 1999)?
At the heart of these inquiries is the recognition that the present and future paths of environmental dilemmas are inextricably linked to dynamics of coupled human and biophysical systems (Gunderson and Holling 2002, Folke et al. 2005, MacMynowski 2007). Interdisciplinary research, particularly between social and biophysical scientists, is deemed both essential and urgent to addressing these challenges (Ewel 2001, Kinzig 2001). Shared zeal for increasing interdisciplinarity, as well as widespread regard of difficulties, is evident throughout the discussions.

My goal in the following analysis is not intended to "put the brakes on" this quest for greater interdisciplinarity. Rather, to the contrary, I propose 
that we "pause on the brink" of interdisciplinarity to critically assess the current intellectual landscape. If the goal is to expand interdisciplinary research between social and biophysical sciences, it is not enough to merely identify the philosophical, structural, and conceptual differences that surface at their confluence. It is essential to take the next step and ask why the difference is there and what purposes are served. In this way, we can go forward with greater transparency, mutual respect, and success in integrating diverse forms of knowledge.

The following analysis is structured in three stages. First, I begin by evaluating the current literature on interdisciplinarity, in both the social and biophysical sciences. Second, I suggest, "what's under the surface" through a critical examination of power at the interface between social and biophysical sciences. Third, I introduce a framework to indicate a path forward toward untangling the complexity of the interdisciplinary research endeavor. Much of this critique, and the entire framework for enhancing interdisciplinary research practice, are applicable to interdisciplinary work within social or biophysical sciences. The issues are simply highlighted at their intersection because of the extent of the differences often encountered.

Decades of scholarship in science and technology studies (STS) take the analysis of interdisciplinarity out of the realm of anecdote. Detailed historical perspectives and a substantial theoretical framework for analyzing disciplinarity and interdisciplinarity exist. However, there is almost no overlap between the STS literature on interdisciplinarity and the discussions in ecologyoriented journals. Substantive reasons for this lack of crosscutting work exist.

In the second part of the analysis, I probe the interface between social and biophysical sciences. This area has received relatively little attention by analysts of interdisciplinarity. By this I mean that there is concern about what impedes the practice of interdisciplinary research, i.e., usually a catalog of barriers or boundaries, and then discussion of the goals of interdisciplinary research, which usually takes the form of questions to be addressed or vague exhortations for the advancement of knowledge. This discussion is particularly directed at the environmental sciences, though many points are more broadly relevant. As such, references to biophysical sciences have disciplines such as ecology and geology in mind; the epistemological situations further afield, such as in theoretical physics or cosmology, are quite different. As I will discuss, there is much diversity within social and biophysical sciences, but some general trends can be used as starting points for analysis and reflection.

Deconstruction without proposing an alternative perspective and practical foundation will not improve the substance and impact of interdisciplinary knowledge generation. To this end, I propose four possible scenarios for how an interdisciplinary undertaking might unfold, with specific implications for the resulting research. Then, to constructively confront the issues discussed in the preceding sections, I outline a three-stage process to enhance the transparent development of interdisciplinary research. First, there is differentiation of the analytical elements of the research, then clarification of purposes, and finally, the steps toward intellectual synthesis. As interdisciplinary research pushes further and deeper, particularly as core philosophical and analytical differences are encountered, consideration of these issues will be essential to intellectual progress and successful collaboration.

Interdisciplinary environmental research has much more potential to be realized. The initial examination that I undertake here, and hope that others will continue, is intended to enhance our understanding of the processes that shape the form and function of the intellectual ecosystem of linked social-biophysical sciences.

\section{APPROACHING DISCIPLINARITY AND INTERDISCIPLINARITY}

To begin the exploration of interdisciplinarity, in this section, I review how interdisciplinarity has been approached, first, in biology- and ecologyoriented journals, and then by scholars of science and technology studies. The purview of this analysis is articles discussing interdisciplinarity, not publications or studies exemplifying interdisciplinary research.

As noted in the introduction, interest in interdisciplinarity has surged in environmental science. All in all, there is a lively desire to do more interdisciplinary research and to do it better. Authors have considered interdisciplinary research challenges associated with funding, degree 
granting, and publishing (Golde and Gallagher 1999, Naiman 1999, Pickett et al. 1999), and the cultural and discursive differences between disciplines (Wear 1999). Repeatedly, issues raised include differences in the presentation of research, conflicting understandings of shared vocabulary, incompatible classifications of phenomena (i.e., "mixed taxonomies," Lele and Norgaard 2005), the status of interdisciplinary publications, and the challenges of peer review. Other authors have considered how to improve the execution of interdisciplinary research. For instance, the STRAP method is a largely instrumental approach that considers substantive knowledge, techniques, range of intellectual skills, administrative units, and personnel (Janssen and Goldsworthy 1996). Heemskerk and co-authors (2003) discuss how conceptual models can be used as a starting point for interdisciplinary discussions.

However, evaluations of interdisciplinary research in journals targeted at biophysical scientists include virtually no citations from the social science literature on disciplinarity and interdisciplinarity; even of one of the most widely cited books on the history, theory, and practice of interdisciplinarity is absent (i.e., Klein 1990). Likewise, in the social science literature, there are virtually no citations from the biophysical literature. The two discussions are running in parallel with stunningly little crossover.

Most biophysical scientists might be surprised to find out that the literature about interdisciplinarity extends back over 50 yr (e.g., Wohl 1955, Mathiasson 1968) and has been extensive for nearly 30 yr (Chubin 1976, Mar et al. 1976, Becher 1989, Klein 1990, Easton and Schelling 1991, MesserDavidow et al. 1993, Gibbons et al. 1994). Thus, consideration of the movement of knowledge between disciplines is not a recent development in response to awareness of coupled socialbiophysical systems and/or the demands of postnormal science (Functowicz and Ravetz 1993). In fact, the first reported mention of the need for increased interdisciplinarity in science was in 1929 (Balsiger 2004).

Early works on "disciplinary migration," or interdisciplinarity, identify many familiar hurdles to the progress of people and ideas in academia, $i$. e., conceptual differences, jargon, social networks, and different literatures (Lackie 1975, Chubin 1976). These concerns about crossing disciplines and research domains have been taken up more recently in the literature on boundaries (see, for review, Lamont and Molnar 2002), and particularly, "boundary work" (see, for review, Klein 1996). Boundary work is defined as "those acts and structures that create, maintain, and break down boundaries," and in particular, it involves "the processes whereby legitimacy and cognitive authority are attached to knowledge" (Fisher 1989:162). Boundary work occurs at many levels, such as between individuals or between organizations, as well as through many outlets, such as popular media, scientific journals, or legal testimony.

With regard to scientific knowledge, boundary work has many permutations. Analyses of boundary work within and between disciplines have been undertaken (e.g., Fisher 1989, Star and Griesemer 1989, Zerubavel 1995, Klein 1996). There is an extensive literature on boundary work between science and nonscience (e.g., Gieryn 1983, 1999) and relations between science, government, and the public (e.g., Jasanoff 1987). And then there is boundary work between science and indigenous knowledge (e.g., Galmiche-Tejeda 2004, Sillitoe 2004). All of these applications have some, and often very direct, relevance to the interdisciplinary environmental research endeavor, as well as the interface of that science with society.

A major discussion in the literature on disciplinary involves the nature of the discipline itself, whether the disciplines are largely closed structures, difficult to penetrate and intellectually self-sustaining (Becher 1989, Klein 1990, Easton and Schelling 1991) or more flexible, nebulous entities (Zerubavel 1995). Authors have explored how ideas move between different social and intellectual contexts. Herein there are some clear parallels with discussions in the biophysical literature. Heemskerk and co-authors (2003) report the results of using conceptual models as a tool for bridging disciplinary boundaries in ecology. Star and Griesemer (1989) advanced the concept of conceptual and rhetorical "boundary objects," which make new understandings, communication, and translations between social worlds possible. Thus, the social science literature has the potential to be informative in analytical perspective as well as provide a theoretical framework for discussions of interdisciplinarity. Likewise, examples and experiences of environmental research presented elsewhere can potentially inform social scientists studying interdisciplinary activity. 
The history of nonconsultation is not without basis. On the biophysical side, the literature has been largely instrumental, i.e., "doing more" and "doing better," and often from a standpoint of projecting an ecological analytical framework onto social questions deemed relevant from an ecologist's point of view (Pickett et al. 1999). On the social side, researchers have focused mostly on structural and process-oriented issues in interdisciplinarity and how they manifest. There is very little of an outcome-driven perspective of how this understanding can change or improve the conduct of interdisciplinary research itself. While nominally approaching the same topic, the goals of researchers are fundamentally different, and thus, the research content and structure are incommensurate with each other's aspirations. Simply stated, most of the social scientists are discussing the means of interdisciplinarity without an end in sight whereas the biophysical scientists are ardently promoting an end without deeper consideration of the means involved.

\section{KNOWLEDGE AND POWER AT THE INTERFACE OF SOCIAL AND BIOPHYSICAL SCIENCES}

The meeting of biophysical and social sciences is about more than the exchange of relevant information. As evidenced in the previous sections, the perspectives, experiences, and purposes of the scholars influence which ideas are considered and communicated, even on the very same topic. In particular, in order for interdisciplinary knowledge to be generated, there has been mention of the need to resolve concepts, theories, and incommensurate definitions (Heemskerk et al. 2003, Lele and Norgaard 2005). This is a very challenging part of the interdisciplinary research process, i.e., when the intellectual initiative for innovation meets the potholes of analytical reconciliation, which sometimes become sinkholes. Why is this process of intellectual interdisciplinary reconfiguration so difficult in practice?

The interdisciplinary landscape is traversed by hierarchies, disciplinary power, and the tendency to lump many diverse areas of social analysis together in contrast to one biophysical research area, e.g., ecology. Thus, research is not just an intellectual meeting that results in the reshuffling of relevant data and concepts in a novel way. Interdisciplinary endeavors begin and end with a meeting of values, worldviews, and claims to know something about something, i.e., a knowledge claim. This meeting of sometimes conflicting "knowers," and the according relationship between knowledge and power, has been extensively discussed in many areas of social inquiry. A basic summary of this work, which has broad interpretations, diverse adherents, and many applications, begins with the premise that knowledge is a fundamental part of the construction of worldviews and ethics. Michel Foucault (1980) most notably advanced the inseparability of knowledge/power and this perspective has been taken up in many areas, including understanding human-nature relations (e. g., Tsouvalis 2000). He particularly referred to the social authority of scientific institutions and scientists' pre-eminent position to arbitrate claims to "truth." Knowledge is at the heart of science; and therefore, so is the exercise of power.

With regard to the environment, numerous authors have described the use of scientific knowledge in the construction of images, intentions, and understandings of nature (e.g., Merchant 1980, Haraway 1991, Wallace 1996). As a constructor and evaluator of the reality of environmental concerns, scientific knowledge claims take on a role as a mediator of power, in addition to basic informative and descriptive purposes. In practical terms, this has been well known and exploited by the environmental movement (Haila and Levins 1988, Benton and Short 1999, Pedynowski 2003b).

What does this insight bring to the table of interdisciplinary research? Biophysical and social scientists are not just bringing information and different understandings of biophysical and social systems with them. Those knowledge claims have differential power associated with them: within the sciences, between social and biophysical sciences, and between science and society. Correspondingly, in the science and technology studies literature, the original interpretation of knowledge/power in science is being revisited. First, science is often inaccurately homogenized, neglecting the diversity of approaches to research and the types of knowledge claims that result (Pedynowski 2003a). Second, the power attributed to knowledge is heterogeneous; environmental debates have many actors with different claims and different levels of social power (Lahsen 2005). These observations of differential knowledge, and thus differential power, are critical for understanding the interface between social and biophysical sciences. 
Thus, reconciling different biophysical and social models of the world is in one part about how those usefully represent reality for the explicit research goals, and in another part, it is about the power that those approaches bring with them. What does power mean in this context? Power can manifest in many ways: an accepted account of an environmental problem, individual scientific status, the inclusion or exclusion of researchers, relative impacts of research findings, access to resources, or perceived relevance to policy decisions, for example (Caldwell 1990, Bowler 1993, Budiansky 1995). In other words, power is synonymous with influence, authority, and validity, and it can be exercised in many overt and subtle social and institutional venues.

Although there have been extensive discussions of the barriers and challenges associated with interdisciplinarity, the finger has not been directly pointed at the exercise of differential power by social and biophysical scientists, within academia and beyond. To probe more deeply, it is necessary to examine a frequent issue of conflict and misunderstanding between many social and biophysical scientists: how to deal with subjectivity in research.

A deep normative current persists that valorizes mathematics and physics as the objective scientific ideal and views other research, particularly the in social sciences, to be trailing behind in the quest for rigor and valid knowledge (Taylor 1996). A claim to pure objectivity is a claim to know the "truth," and therefore, a claim to authority and power (Haraway 1992, Merchant 1992, Feyerabrand 1993). Accordingly, many of the social sciences, with their overt recognition of subjectivity on the part of the researcher, bring less social power to the interdisciplinary meeting ground than biophysical sciences. Aspects of differential influence and control have been noted frequently in the both the ecological and social literature on interdisciplinarity (Heberlein 1988, Redclift 1998, Freudenburg 2002). Furthermore, approaches to objectivity and subjectivity are quite varied within the social and biophysical sciences, with perceptual and powerrelated differences between areas of inquiry, e.g., cultural anthropology and neoclassical economics. It should also be noted that objectivity can destabilize knowledge and power through challenge of previous research findings; moreover, in nonscientific contexts, subjectivity, through avenues such as revealed knowledge, can wield considerable power.
The tension over subjectivity and objectivity percolates through discussions of interdisciplinarity. Set in contrast to the biophysical or natural sciences, the social sciences are often portrayed as disunified, in constant conflict, or poorly developed in their theoretical foundations. This can also function as an over-arching, normative presumption. For instance, when writing of impediments to research between social and biophysical scientists, Heberlein (1988:6) identified "real and serious weakness" in the social sciences owing to being "less developed than the natural sciences in terms of theory, data, method, and tradition." Gibson and co-authors (2000:217) discuss how "social scientists have worked with scales of less precision and of greater variety" than the "relatively well-defined hierarchical systems of analysis" used by natural scientists. If the full breadth of social systems is considered, and the according panoply of researchers included, then it can be said that there is greater variety, less consistency, and less cohesion than within the natural sciences.

The interpretive problem is that the theoretically, methodologically, and traditionally cohesive natural sciences under consideration are centered on ecology and associated research areas, e.g., forestry. This represents a limited subset of the researchers who work on the environment. If authors made more symmetrical comparisons of theory and data across the breadth of natural scientists, including chemists, geologists, microbiologists, wildlife epidemiologists, and ecologists, then a more comparable picture of disunity and inconsistently developed foundations would result.

The characterization of internal debate in the social sciences is also related, in part, to these asymmetries. Lele and Norgaard (2005) list a spectrum of explanations of environmental degradation, including diverse actors such as neoclassical economists, ecofeminists, and political economists, to highlight the competition between social scientists for explanatory supremacy. In parallel, it might be possible to frame a question of environmental change from different dimensions and illustrate deep division amongst natural scientists. Is a species' gene flow disrupted and phenotypic adaptive capacity reduced? Is the climate changing? Does that mean increased variability or longer summers? Have the microbe communities been affected by changed nitrogen cycling? Are invading barred owls outcompeting spotted owls? Which explanation is correct? Some of these? Maybe all of these. It depends upon what 
question is asked, how the system is characterized, and where the boundaries are placed for both social and biophysical sciences.

The tensions and differences in biophysical sciences of the environment, although extensive, do differ from social sciences in a critical way: they are relatively epistemologically and ontologically constrained. In other words, most biophysical environmental scientists share fundamental, positivist assumptions about the law-like nature of the systems that they study and the search for universal principles of explanation (e.g., Bauer 1990). Even debates over the relative value of experimental and historical research (Roush 1995, Cleland 2002) are situated within these philosophical boundaries. These axioms about the nature of reality influence, if not largely drive, the presumptions about the relationship between the researcher and the subject/object of study and the modeling of system processes. Thus, the interdisciplinary differences are more tractable as long as those assumptions about the system and the researcher persist.

This presumed unity of the biophysical or natural scientists in the context of environmental science remains a potent analytical and normative point. The debates about subjectivity and role of the researcher, widespread in social inquiry, as well as the differences in resulting conceptual models, have been generally approached by biophysical environmental scientists with more reluctance than welcoming opportunity. Questions of rigor in interdisciplinary research process and products persist (Lau and Pasquini 2004). Sillitoe (2004) has even argued that social science perspectives on subjectivity have generated a backlash against interdisciplinary endeavors, with researchers retreating to more solidly established disciplinary methods and theory.

It could be said that there is a widespread sentiment amongst biophysical scientists that "we don't want to go there" with regard to addressing the diverse approaches to knowledge and the role of researcher. Going "there," however, may well be a fundamental part of situating science, particularly environmental science, in society. Bradshaw and Bekoff (2001:461), writing in an ecology journal, summarize:

Integrating biophysical and social sciences means bringing back the very concepts and attributes, e.g., subjective experience, that, by their historical exclusion from science, defined science. Incorporating social sciences into biophysical studies has brought attention to not only the interactions between humans and ecological systems but also to how science functions as part of a larger system of knowledge, nature, and society.

A full discussion of subjectivity and interdisciplinarity is beyond the scope of this paper. Suffice to say, as long as the asymmetries presented above persist, they will impede accurate, balanced appraisals of the potential contributions of different objective and subjective approaches to understanding human and biophysical systems. The debate over subjectivity and objectivity will continue to be a flashpoint at the meeting ground of social and biophysical sciences, unless explicit effort is made to make differences transparent, understood, and open to negotiation.

Therefore, if the goal is to increase interdisciplinary research between social and biophysical sciences, it is not enough to point out the philosophical, structural, and conceptual differences that arise at their confluence. It is essential to take the next step and ask why the difference is there and what purposes are served. I will discuss the explication of purposes further in a later section. In next section, however, I will offer an interpretive guide of how the meeting of social and biophysical sciences could proceed and the implications for the type of research that results.

\section{FOUR SCENARIOS OF INTERSECTING KNOWLEDGE}

The abstractions of power and knowledge play out in very real research outcomes, depending on the goals and relative influence of the individuals or groups involved. What interdisciplinary research projects are undertaken, which disciplines are involved, how conflicts are resolved, and the acceptance of the research by the rest of the scientific community are due, in part, to the differentially perceived power of the research and researchers. Of course, clearly, the quality and relevance of the research, and the structural aspects of knowledge assimilation, e.g., discourse, publication availability, professional networks, 
have fundamental roles as well. Whereas those have been elaborated elsewhere, here I am emphasizing the connection between knowledge claims and power, in its many permutations, at the interdisciplinary interface.

The encounter that ensues when different forms of knowledge intersect spans the range from divisive conflict to radical transformation (Fig. 1). In this section, I describe four possible scenarios, all of which can lead to different types of research being conducted. These are starting points for reflection and intended as working model to facilitate discussion, debate, and reflection amongst interdisciplinary environmental scientists. An actual research endeavor or situation most likely falls somewhere between these discrete positions, even moving along the continuum during the evolution of the project itself. Thus, the continuum is dynamic and multidimensional. I discuss these scenarios at the interface between social and biophysical environmental sciences, but the structure certainly has relevance in other contexts in which knowledge claims collide, e.g., traditional ecological knowledge, religion (see Cabezon 2003, Proctor 2005).

The first scenario is one of conflict. Conflict is one possible outcome for research interactions, or more likely, prevents the collaboration from beginning in the first place. Research might start with an interdisciplinary intent, but researchers go their separate ways. Irreconcilable differences are identified, often of a normative nature, which results in hostile maintenance of boundaries rather than the more ambivalent scenario described next. This situation is more apparent at the interface of science and nonscience than between researchers accepted as within the broad rubric of environmental science.

The second scenario is based upon tolerant ambivalence. Researchers from different disciplines can amicably coexist, even contribute to the same project, but the analytical domains are largely separate. There is maintenance of boundaries, but a largely tolerant, pluralist perspective prevails. This is one portrayal of interdisciplinary research between social and biophysical sciences; social systems are distinct from biophysical systems and inherently require different approaches. For example, an ecologist does research on grizzly bear populations and dispersal whereas a human geographer investigates the organization of wildlife management agencies. In this context, there is little space for critique of the ideas and constructs presented within the scientific context itself. Given their separate realms, differences are acceptable and tolerable. Historical boundaries are maintained and knowledge claims largely circulate within their traditional domains to audiences with similar philosophical and analytical orientations.

Overt conflicts of power are largely minimized by this separation, but there can be issues in the distribution of research resources and the balance of results presented. Many research projects involving biophysical and social scientists, or even comprised entirely of different disciplines of biophysical and social sciences, successfully proceed in this manner. It can be very fruitful, as different skills are brought to a research problem and perspectives are laid side-by-side. However, the qualitative transformation of knowledge is limited and knowledge claims mostly cycle back into the research community from which they came.

The third scenario is one of mutual identification and cooperation. There are theories and analytical tools that can be transferred if effort is put into communication, consistency of models and concepts, and crossover applications of theory. The basic philosophical underpinnings are shared. This approach presumes recognition of fundamental similarity and purpose, either in methods or approaching a similarly conceived system with different methods. One example is mathematical ecology and economics. Tools of ecological and economic system analysis, with the movement of theory, e.g., game theory, can bring new characterization and analysis of an issue or situation that would not be independently possible. There are notable shifts in the boundaries of disciplines and recombinations of researchers, publications, and ideas, with the possibility for new research programs to form. However, rather than radical reconceptualization of the research topic, the initiative is to ask different questions within the analytical framework of one discipline (e.g., Pickett et al. 1999). Much interdisciplinary environmental research is currently in this category, with exchanges between social and biophysical scientists of similar philosophical orientations, e.g., engineers, economists, climatologists, ecologists, and shared analytical structures, e.g., approaches to scale, systems thinking, etc.

The fourth scenario involves a fundamental reorientation and recombination of knowledge 
Fig. 1. A schematic of the continuum of intersecting knowledge claims. Four specific scenarios are identified, but most interdisciplinary research or situations will be situated between these discrete points.

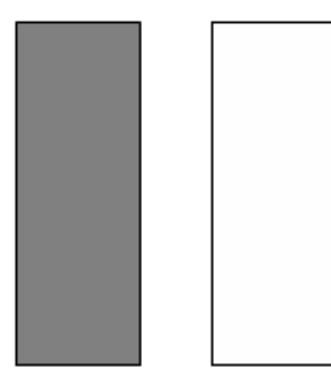

Conflict

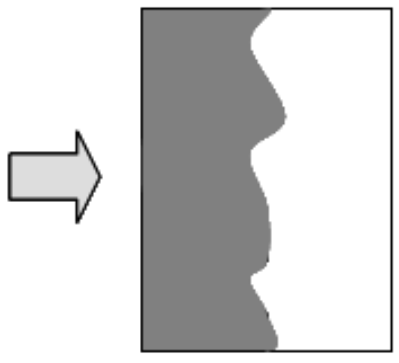

Tolerant Ambivalence
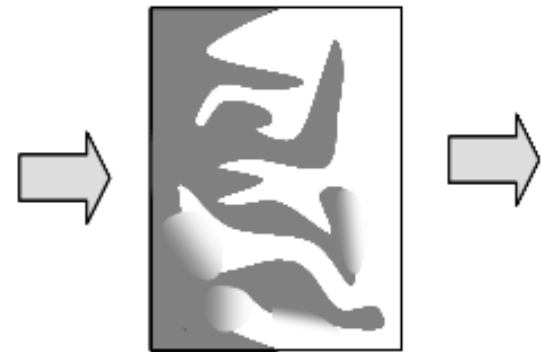

Cooperation \& Identification

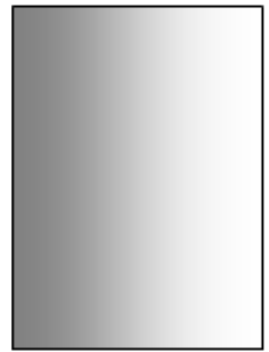

Transformation claims. It begins with recognition of a common problem at the intersection of very different conceptual, philosophical, and methodological standpoints. The understanding of the problem, the research design, and the analysis recombine elements from intellectual lineages with little similarity, past cooperation, or shared theory and philosophy. Research of this sort, at a large scale, is minimal at this time, but initial examples could include ethnobotany and efforts to understand and conduct natural resource management with traditional ecological knowledge. Outside of environmental science, consciousness studies are an emergent example of this scenario. Very different philosophical, theoretical, and empirical formulations, from realms as different as traditional Tibetan Buddhist practice to neuroscience, are being brought to bear on research questions and frameworks of mind and being (see edited volume by Wallace 2003).

A core part of furthering radically transformative research directions is not only to develop the opportunity for it to be explored and executed, but also for its acceptance and use. From another perspective: the intellectual product cannot be developed in isolation of its consumers and marketplace. This requires a much larger scale interest and social change, again, both within science and between science and society, in order for the work to go beyond isolated projects. Traditional associations with research domains, boundaries, and the distribution of power need to be broken down and transformed. This is a multilevel, intensive reflection and re-creation process. Thus, it is understandable why the majority of interdisciplinary research, particularly between social and biophysical sciences, has been situated between the second or third scenario above. Some groundwork for the acceptance and influence of the knowledge claims already exists, and even so, there are significant barriers.

These four scenarios are inherently multiscalar and transscalar. Each could manifest at many levels, such as between individual researchers, amongst groups on a research project, all the way to the potential for work between entire disciplinary lineages.

Likewise, the many institutional and educational aspects of interdisciplinary science are also highly relevant. Which researchers are included or excluded from departments or institutes? To which theories or models are students exposed? Each of these questions can be examined at the level of an individual university all the way through the international community of scholars in a particular discipline or research domain. These scenarios are intended to provoke questions, and be part of an ongoing dialogue, in the development of an interdisciplinary collaboration. Which scenario is our work most like? Is this our goal? How different would the research look if another approach to 
reconciling difference were undertaken? Finally, how and why is the research proceeding in the way that it is?

\section{DIFFERENTIATION, CLARIFICATION, AND SYNTHESIS}

The final question in the last section is the challenge of every interdisciplinary research project to answer. In order for interdisciplinary research to proceed more transparently in terms of the recombination of ideas and making the power associated with knowledge claims explicit, interdisciplinary environmental research needs to consciously embark on a process of differentiation and clarification before, or while, moving toward synthesis. The extent of the success of this engagement is what moves the meeting of social and biophysical scientists into one of the different scenarios presented in the last section. In the differentiation-clarification-synthesis process, the less visible aspects of science, which can be comfortably tucked away when not confronted by contrast, come out of the shadows (Fig. 2).

The first step of differentiation, i.e., specifying differences in approaches to knowledge, methods, research motivations, and the relationship between the research and researcher, is both straightforward and complex. On one hand, the differentiation is undertaken by individual researchers collaborating at the level of a research project or other group endeavor. On the other hand, this local effort is also part of a larger philosophical differentiation process to recognize the diversity of types of knowledge that are all considered to fall under the rubric of science (Galison and Stump 1996, Pedynowski 2003a). Many of the following questions seem obvious, but might yield surprising results if a collaborator has a very different perspective. The differentiation process can be undertaken at any stage in research, ideally at the outset, but also likely, iteratively as research evolves. In particular, I have invoked this process at a point of conflict or confusion, when it appears that a collaborator and I are discussing the same thing, but there is some assumption or issue that is preventing us from moving forward with research design or interpretation of results.

First, there are questions about how the knowledge itself is generated. How would I know "good science" if I saw it? What are the standards of validity, reliability, and dealing with uncertainty that are being used? What are the limits to our knowledge about this system, or, on a grand scale, reality itself? What are assumptions about the nature of the system? How does theory link data and analysis? What does theory look like? Is it ideally an equation or is it a web of inter-related meaning? These questions can be forgotten as a scholar is surrounded by the particular norms of a research community. Moreover, with increased focus on the substance of analysis, e.g., statistics, interpretation of results, the bigger picture questions about the underlying framework of the research program might receive less and less intellectual space. Conversely, debate over results can also invigorate taking a step back to reconsider core assumptions.

Second, there are questions about the purpose of the research. What is the overall intellectual motivation for this research: to predict, to explain, or to interpret? What are the goals for this specific research project? The underlying motivation of a research project is inseparable from its design. Therefore, conflicts concerning the choice of methods and expected outcomes can be closely linked to differences in goals.

Third, there is the relationship between the researcher and the research to consider. Do I see myself as inside or outside of what I am studying? How were these boundaries drawn? What implications are there for that position and the subsequent use of the research? Finally, there are the larger purposes of this research. How does the research product fit into intellectual goals or addressing societal needs? How do the previous choices on philosophy, theory, and positionality relate to that answer?

Ultimately, differentiation and clarification are not separate. In fact, many of the clarifying questions immediately follow from the enumeration above. After asking about the choice of methods, the next question is to probe why these particular methods are used to answer this type of question? In another example, after identifying goals, it is critical to ask how those goals, and the intended final product are reflected in research design. Is another design possible with different, or additional, methods that might produce another answer to the question?

In this context, clarification specifically means reflection on the purpose of differences. What is the rationale for the choices that produced those differences? The purposes can be epistemic, 
Fig. 2. The process of differentiation, clarification, and synthesis. Key questions at each stage are highlighted.

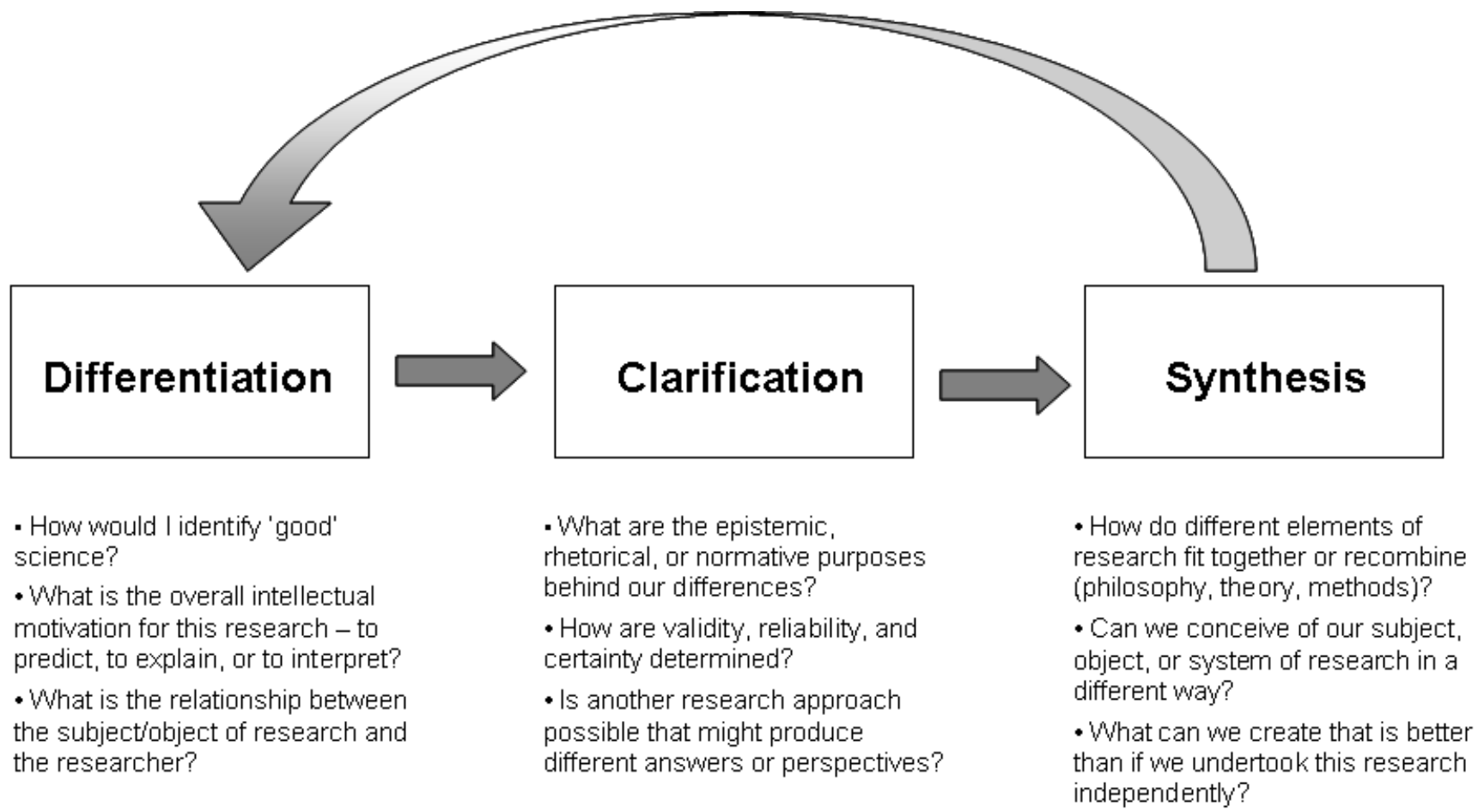

rhetorical, metaphorical, or normative. Or, all of those in a tangle of analytical rationale, precedent, and convention. In other cases, there might be historical assumptions, with political and ideologyladen roots, to be revisited (see Wallerstein 1995 on the boundaries of social science disciplines). In practice, Scoones (1999) contrasts the expectation of dynamic vs. stable systems in social and ecological research. Such a fundamental, and potentially unrecognized, conceptualization of the system being studied has major implications for the design of research. This influence of ecological dynamics upon geographical and anthropological ideas about society has been examined with consequences for research design and analysis (Zimmerer 1994, Kottak 1999).

An answer of "this is the way it has usually been done" or "it's an accepted standard" is an invitation to probe deeper as well as to consider other possible answers. Here are dim corners in which power can be wielded through an uncritical, unreflective regard of difference and its intellectual and social basis. Other authors have recognized the valueladen aspects of many analyses and assertions (Lele and Norgaard 2005, for an example of economics). However, simply identifying the existence of values will not dissolve the web of power that can be overtly or covertly transferred into the generation of knowledge. An active engagement with the process of valuation, and its analytical implications, is necessary to transform that power and make scientific interpretation and intellectual recombination as transparent as possible. This is why the differentiation and clarification of knowledge claims needs to become a fundamental part of the process of interdisciplinary research.

Synthesis, the final step of this engagement, is the intellectual fruit after the labor of differentiating and clarifying the research models, concepts, and philosophies at hand. Where does "this" fit in 
relation to "that"? "This" and "that" could be any of the differentiated elements above, e.g., methods, validity, philosophy. What should we keep and what should we tweak? What do we need to invent to go forward? The latter is the promising part of interdisciplinary research. If there are no major differences in intellectual elements, then maybe there is an opportunity to bring other researchers with different perspectives to the table. After all, the potential for new insight and intellectual recombination is at the heart of the motivation for undertaking interdisciplinary research in the first place. After all of the effort put into differentiation and clarification, what can we create that is better than if we undertook this research independently?

The process of differentiation, clarification, and synthesis is likely to be an iterative undertaking, repeating itself throughout research design, resolving research problems, interpreting results, and determining conclusions. For instance, Heemskerk and co-authors (2003) suggest using conceptual models in interdisciplinary discussions. These could be both process and product; in other words, the elements of conceptual models can be differentiated and clarified, with the potential for a new synthesized model resulting from new perspectives. As knowledge is evolves and changes, the process continues. In this way, the cycle of differentiation, clarification, and synthesis can be likened to the "hermeneutical circle" (e.g., Taylor 1985). Researchers are engaged in an ongoing, reflexive process of peeling the layers off how they understand the tools and theories that they use to explain and understand coupled social-biophysical systems.

\section{CONCLUDING REMARKS}

The analysis herein has itself modeled the process of differentiation, clarification, and synthesis. This inquiry began with an examination of the differences in how social and biophysical scientists have approached the topic of interdisciplinarity. Next, I considered how greater depth and clarity could be brought to understanding the intersection of social and biophysical sciences through a consideration of knowledge/power and the four scenarios of intersecting knowledge. Finally, I introduced a process with the goal of enhancing the synthetic potential of interdisciplinarity between social and biophysical scientists.
Although the process of differentiation-clarificationsynthesis has been described predominantly at the level of intellectual questions, there are many more potential applications. Clearly, interdisciplinary research endeavor has a fundamental social aspect, which other authors have elaborated (Janssen and Goldsworthy 1996, Naiman 1999). The social factors of trust, cooperation, patience, and openness are as key to interdisciplinary success as the ideas themselves (Daily and Ehrlich 1999). These issues are not restricted to research design and execution; they also insert themselves into peer review, funding processes, and professional appointments. Thus, the process of conscious differentiation and clarification have purview beyond the research project itself. Further discussion of those aspects of interdisciplinarity, and their relation to power, are beyond the scope of this paper.

The point remains that the progress of the interdisciplinary intellectual effort is fundamentally entwined with the social research process and societal context of "doing science." It is at this entwining that knowledge mixes with power. This observation is a core perspective of science and technology scholars and investigations into the sociology of science. As practicing scientists, the choice is whether to recognize the situation and deal with the implications as transparently, methodically, and consciously as possible, or to deny this aspect of the interdisciplinary interface and let these forces operate behind a screen of tradition, assumptions, and unexplicated values.

Responses to this article can be read online at:

http://www.ecologyandsociety.org/vol12/iss 1/art20/responses/

\section{Acknowledgments:}

Many colleagues contributed to these ideas through critique and example, in particular, I thank $T$. $L$. Root and S. H. Schneider for continued encouragement and interdisciplinary debate. D. G. MacMynowski and K. N. Cahill provided valuable comments on an earlier version of this manuscript. Three anonymous reviewers also provided constructive comments. An anonymous reviewer provided the observation that objectivity has the potential to destabilize accepted knowledge and subjectivity can wield power in nonscientific contexts. 


\section{LITERATURE CITED}

Balsiger, P. W. 2004. Supradisciplinary research practices: history, objectives, and rationale. Futures 36:407-421.

Bauer, H. H. 1990. Barriers against interdisciplinarity: implications for studies of science, technology, and society (STS). Science, Technology, and Human Values 15:105-119.

Becher, T. 1989. Academic tribes and territories: intellectual enquiry and the cultures of disciplines. Society for Research into Higher Education and Open University Press, Bristol, Pennsylvania, USA.

Benton, L. M., and J. R. Short. 1999. Environmental discourse and practice. Blackwell, Oxford, UK.

Bowler, P. J. 1993. Science and the environment: new agendas for the history of science? Pages 1-23 in M. Shortlund, editor. Science and the environment: new agendas for the history of science? British Society for the History of Science, London, UK.

Bradshaw, G., and M. Bekoff. 2001. Ecology and social responsibility: the re-embodiment of science. Trends in Ecology and Evolution 16:460-465.

Budiansky, S. 1995. Nature's keepers: the new science of nature management. Orion Books, London, UK.

Cabezon, J. I. 2003. Buddhism and science: on the nature of the dialogue. Pages 35-70 in B. A. Wallace, editor. Buddhism and science: breaking new ground. Columbia University Press, New York, New York, USA.

Caldwell, L. K. 1990. Between two worlds: science, the environmental movement, and policy choice. Cambridge University Press, Cambridge, UK.

Chubin, D. E. 1976. The conceptualization of scientific specialties. The Sociological Quarterly 17:448-476.

Cleland, C. E. 2002. Methodological and epistemic differences between historical science and experimental science. Philosophy of Science 69:474-496.
Daily, G., and P. R. Ehrlich. 1999. Managing Earth's ecosystems: an interdisciplinary challenge. Ecosystems 277-280.

Easton, D., and C. S. Schelling, editors. 1991. Divided knowledge across disciplines and across cultures. Sage Publications, Newbury Park, California, USA.

Ewel, K. C. 2001. Natural resource management: the need for interdisciplinary collaboration. Ecosystems 4:716-722.

Feyerabrand, P. 1993. Against method. Verso, London, UK.

Fisher, D. 1989. Boundary work: a model of the relation between power and knowledge. Knowledge: Creation, Diffusion, Utilization 10:156-176.

Folke, C., T. Hahn, P. Olsson, and J. Norberg. 2005. Adaptive governance of social-ecological systems. Annual Review of Environment and Resources 30:441-473.

Foucault, M. 1980. Truth and power. Pages 109-134 in C. Gordon, editor. Truth and power. Pantheon, New York, New York, USA.

Freudenburg, W. R. 2002. Scientific expertise and natural resource decisions: social science participation on interdisciplinary scientific committees. Social Science Quarterly 83:119-136.

Functowicz, S. O., and J. R. Ravetz. 1993. Science for the post-normal age. Futures 31:739-755.

Galison, P. J., and D. Stump. 1996. The disunity of science: boundaries, contexts, and power. Stanford University Press, Stanford, CA.

Galmiche-Tejeda, A. 2004. Who is interdisciplinary? Two views, two goals, professionals and farmers. Interdisciplinary Science Reviews 29:77-95.

Gibbons, M., C. Limoges, H. Nowotny, S. Schwartzman, P. Scott, and M. Trow. 1994. The new production of knowledge. Sage, London, UK.

Gibson, C. C., E. Ostrom, and T. Ahn. 2000. The concept of scale and the human dimensions of global change: a survey. Ecological Economics 32:217-239.

Gieryn, T. F. 1983. Boundary-work and the 
demarcation of science from non-science: strains and interests in professional ideologies of scientists. American Sociological Review 48:781-795.

Gieryn, T. F. 1999. Cultural boundaries of science: credibility on the line. University of Chicago Press, Chicago, Illinois, USA.

Golde, C. M., and H. A. Gallagher. 1999. The challenges of conducting interdisciplinary research in traditional doctoral programs. Ecosystems 281-285.

Gunderson, L., and C. Holling. 2002. Panarchy: understanding transformations in human and natural systems. Island Press, Washington, D.C., USA.

Haila, Y., and R. Levins. 1988. Humanity and nature: ecology, science, and society. Pluto, London, UK.

Haraway, D. 1991. Simians, Cyborgs, and women. Free Association Books, London, UK.

Haraway, D. 1992. Primate visions: gender, race, and nature in the world of modern science. Routledge, New York, New York, USA.

Heberlein, T. A. 1988. Improving interdisciplinary research: integrating the social and natural sciences. Society and Natural Resources 1:5-16.

Heemskerk, M., K. Wilson, and M. PavaoZuckerman. 2003. Conceptual models as tools for communication across disciplines. Conservation Ecology 7:8-12.

Janssen, W., and P. Goldsworthy. 1996. Multidisciplinary research for natural resource management: conceptual and practical implications. Agricultural Systems 51:259-279.

Jasanoff, S. S. 1987. Contested boundaries in policy-relevant science. Social Studies of Science 17:195-230.

Kinzig, A. P. 2001. Bridging disciplinary divides to address environmental and intellectual challenges. Ecosystems 4:709-715.

Klein, J. T. 1990. Interdisciplinarity: history, theory, and practice. Wayne State University Press, Detroit, Michigan, USA.
Klein, J. T. 1996. Crossing boundaries: knowledge, disciplinarities, and interdisciplinarities. University Press of Virginia, Charlottesville, Virginia, USA.

Kottak, C. P. 1999. The new ecological anthropology. American Anthropologist 101:23-35.

Lackie, G. 1975. Interdisciplinary research in the university setting. University of Manitoba, Winnipeg, Manitoba, Canada.

Lahsen, M. 2005. Technocracy, democracy, and U. S. climate politics: the need for demarcations. Science, Technology, and Human Values 30:137-169.

Lamont, M., and V. Molnar. 2002. The study of boundaries in the social sciences. Annual Review of Sociology 28:167-195.

Lau, L., and M. W. Pasquini. 2004. Meeting grounds: perceiving and defining interdisciplinarity across the arts, social sciences and sciences. Interdisciplinary Science Reviews 29:49-64.

Lele, S., and R. B. Norgaard. 2005. Practicing interdisciplinarity. BioScience 55:967-975.

MacMynowski, D. P. 2007. Across space and time: social responses to large scale biophysical systems. Environmental Management, in press.

Mar, B., W. Newell, and B. Saxberg. 1976. Interdisciplinary research in the university setting. Environmental Science and Technology 10:650-653.

Mathiasson, J. 1968. My discipline is better than your discipline: some barriers to interdisciplinary research. Canadian Review of Sociology and Anthropology 5:263-275.

Merchant, C. 1980. The death of nature. Harper Collins, San Francisco, California, USA.

Merchant, C. 1992. Radicalecology: the search for a livable world. Routledge, New York, New York, USA.

Messer-Davidow, D. R. Shumway, and D. J. Sylvan. 1993. Knowledges: historical and critical studies in disciplinarity. University Press of Virginia, Charlottesville, Virginia, USA.

Naiman, R. J. 1999. A perspective on interdisciplinary science. Ecosystems 2:292-295. 
Pedynowski, D. 2003a. Science(s)-which, when, and whose? Probing the meta-narrative of scientific knowledge in the social construction of nature. Progress in Human Geography 27:761-778.

Pedynowski, D. 2003b. Toward a more "reflexive environmentalism": ecological knowledge and advocacy in the Crown of the Continent Ecosystem. Society and Natural Resources 16:807-825.

Pickett, S., W. R. Burch Jr., and J. M. Grove. 1999. Interdisciplinary research: maintaining the constructive impulse in a culture of criticism. Ecosystems 2:302-307.

Proctor, J. D. 2005. Science, religion, and the human experience. Oxford University Press, New York, New York, USA.

Redclift, M. 1998. Dances with wolves? Interdisciplinary research on the global environment. Global Environmental Change-Human and Policy Dimensions 8:177-182.

Roush, W. 1995. When rigor meets reality. Science 269:313-315.

Scoones, I. 1999. New ecology and the social sciences: what prospects for a fruitful engagement? Annual Review of Anthropology 28:479-507.

Sillitoe, P. 2004. Interdisciplinary experiences: working with indigenous knowledge in development. Interdisciplinary Science Reviews 29:6-23.

Star, S., and J. Griesemer. 1989. Institutional ecology, "translations," and boundary objects: amateurs and professionals in Berkeley's Museum of Vertebrate Zoology, 1907-39. Social Studies of Science 19:387-420.

Taylor, C. 1985. Philosophy and the human sciences. Cambridge University Press, New York, New York, USA.

Taylor, C. A. 1996. Defining Science: a rhetoric of demarcation. University of Wisconsin Press, Madison, Wisconsin, USA.

Tsouvalis, J. 2000. A critical geography of Britain's state forests. Oxford University Press, Oxford, UK.

Wallace, B.A., editor. 2003. Buddhism and science. Columbia University Press, New York, New York, USA.
Wallace, W. A. 1996. The modeling of nature. The Catholic University of America Press, Washington, D.C., USA.

Wallerstein, I. 1995. What are we bounding, and whom, when we bound social research. Social Research 62:839-856.

Wear, D. N. 1999. Challenges to interdisciplinary discourse. Ecosystems 2:299-301.

Wohl, R. 1955. Some observations on the social organization of interdisciplinary social science research. Social Forces 33:374-383.

Zerubavel, E. 1995. The rigid, the fuzzy, and the flexible: notes on the mental sculpting of academic identity. Social Research 62:1093-1106.

Zimmerer, K. S. 1994. Human geography and the "new ecology": the prospect and promise of integration. Annals of the Association of American Geographers 84:108-125. 